\title{
The association of antenatal D-dimer and fibrinogen with postpartum hemorrhage and intrauterine growth restriction in preeclampsia
}

\author{
Hailing Shao ${ }^{1}$, Shichu Gao', Dongru Dai ${ }^{2}$ Xiaomin Zhao ${ }^{1}$, Ying Hua ${ }^{1 *}$ and Huijun Yu ${ }^{1 *}$
}

\begin{abstract}
Background: D-dimer and fibrinogen were verified to be altered in preeclampsia. This study was to evaluate the associations of D-dimer and fibrinogen plasma levels with postpartum hemorrhage or intrauterine growth restriction in preeclamptic women.

Methods: This was a retrospective study that recruited 278 preeclamptic women with singleton pregnancy from January 2016 to December 2019. Patients were allocated into five groups: mild preeclampsia (mPE) ( $n=68)$, mild preeclampsia with postpartum hemorrhage $(m P E+P P H)(n=13)$, severe preeclampsia $(s P E)(n=112)$, severe preeclampsia with postpartum hemorrhage $(s P E+P P H)(n=17)$ and severe preeclampsia with intrauterine growth restriction (SPE+IUGR) $(n=68)$. The antenatal D-dimer and fibrinogen plasma levels were analyzed among the groups. Logistic regression was used to determine the correlation between serum indexes and PPH or IUGR in preeclampsia.

Results: The antenatal D-dimer plasma levels were significantly higher in the sPE+PPH group than that in the sPE group $(2.02 \mu \mathrm{g} / \mathrm{ml}$ versus $1.37 \mu \mathrm{g} / \mathrm{ml}, P=0.001)$, but there was no difference in fibrinogen. Elevated Ddimer was associated with PPH among severe preeclamptic women (adjusted odds ratio (aOR) [95\% Cl]: 3.093 [1.527-6.264], $P=0.002$ ). No differences in D-dimer and fibrinogen were found between the MPE and $\mathrm{mPE}+\mathrm{PPH}$ groups or between the sPE and SPE+IUGR groups.

Conclusions: Elevated antenatal plasma D-dimer level may be associated with postpartum hemorrhage in severe preeclampsia, but not with intrauterine growth restriction. Future prospective clinical trials are needed to investigate the predictive value of D-dimer in postpartum hemorrhage in severe preeclampsia.
\end{abstract}

Keywords: D-dimer, Fibrinogen, Preeclampsia, Postpartum hemorrhage, Intrauterine growth restriction

* Correspondence: wzfeyhy1015@126.com; yuhuijun1997@126.com

'Department of Obstetrics and Gynecology, the Second Affiliated Hospital of Wenzhou Medical University, Wenzhou 325027, China

Full list of author information is available at the end of the article

C C The Author(s). 2021 Open Access This article is licensed under a Creative Commons Attribution 4.0 International License, which permits use, sharing, adaptation, distribution and reproduction in any medium or format, as long as you give appropriate credit to the original author(s) and the source, provide a link to the Creative Commons licence, and indicate if changes were made. The images or other third party material in this article are included in the article's Creative Commons licence, unless indicated otherwise in a credit line to the material. If material is not included in the article's Creative Commons licence and your intended use is not permitted by statutory regulation or exceeds the permitted use, you will need to obtain permission directly from the copyright holder. To view a copy of this licence, visit http://creativecommons.org/licenses/by/4.0/ The Creative Commons Public Domain Dedication waiver (http://creativecommons.org/publicdomain/zero/1.0/) applies to the data made available in this article, unless otherwise stated in a credit line to the data. 


\section{Background}

Preeclampsia (PE), characterized by new-onset hypertension and proteinuria occurring after 20 weeks of gestational age, is a pregnancy-specific disorder involving multiple organ damage [1]. It affects approximately $4.6 \%$ of pregnant women worldwide [2], and is closely associated with adverse pregnancy outcomes, such as intrauterine growth restriction (IUGR) [3], one of the most important causes of death of perinatal infants [4]. In addition, pregnant women with PE are at higher risk of postpartum hemorrhage ( $\mathrm{PPH})$ due to uterine atony [5]. Preeclampsia is a dynamic disease and it can present as mild preeclampsia (hypertension with proteinuria only) or develop rapidly into severe preeclampsia (preeclampsia with impaired function of multiple organs and systems), eclampsia (seizures that occur based on preeclampsia and cannot be explained by any other cause) or HELLP syndrome (hemolysis, elevated liver enzymes and low platelets), resulting in high fetal and maternal mortality [6]. The timing of diagnosis and treatment depends on the clinical manifestations or laboratory indexes caused by target organ damage, which may miss the optimal intervention time.

A prominent feature reported in PE is the more exacerbated hypercoagulable state, containing platelet activation [7], overproduction of thrombin [8] and alterations of fibrinolytic factors [9]. The activation of platelet may cause thrombosis in terminal vascular branches of target organs. The increased thrombin generation is thought to be associated with endothelial dysfunction, platelet activation and pro-inflammatory cytokines. Additionally, anti-type-1 angiotensin II receptor (AT1) autoantibodies stimulate the release of plasminogen activator inhibitor1 (PAI-1) [10]. Fibrin deposition was widely found in PE [10], seemingly suggesting that the balance between coagulation and fibrinolysis was broken up [9]. D-dimer is the ultimate degradation product of a fibrin clot crosslinked by factor XIII [11]. Several studies have explored the associations between D-dimer, fibrinogen and mild PE (mPE) or severe PE (sPE), and the possible value of D-dimer and fibrinogen in predicting PE [3, 12-14]. And we notice that these two indicators alter in pregnancies complicated with IUGR or PPH $[4,5]$.

This study aimed to evaluate the associations of Ddimer and fibrinogen plasma levels with PPH or IUGR in preeclamptic women.

\section{Methods}

We conducted a retrospective cohort control study in the Second Affiliated Hospital of Wenzhou Medical University from January 2016 to December 2019, including 278 preeclamptic women with singleton pregnancy. This study was approved by the Hospital Research Ethics Committee. All PE patients were hospitalized to give birth at this hospital. As is detailedly showed in Fig. 1, PE patients were categorized into five subgroups according to severity and complications (IUGR and PPH) of this disorder, including the mPE $(n=68), \operatorname{mPE}+\mathrm{PPH}(\mathrm{n}=$ 13), sPE $(n=112), \operatorname{sPE}+P P H(n=17), \operatorname{sPE}+\operatorname{IUGR}(n=68)$ groups. The diagnosis of $\mathrm{PE}$ is strictly following

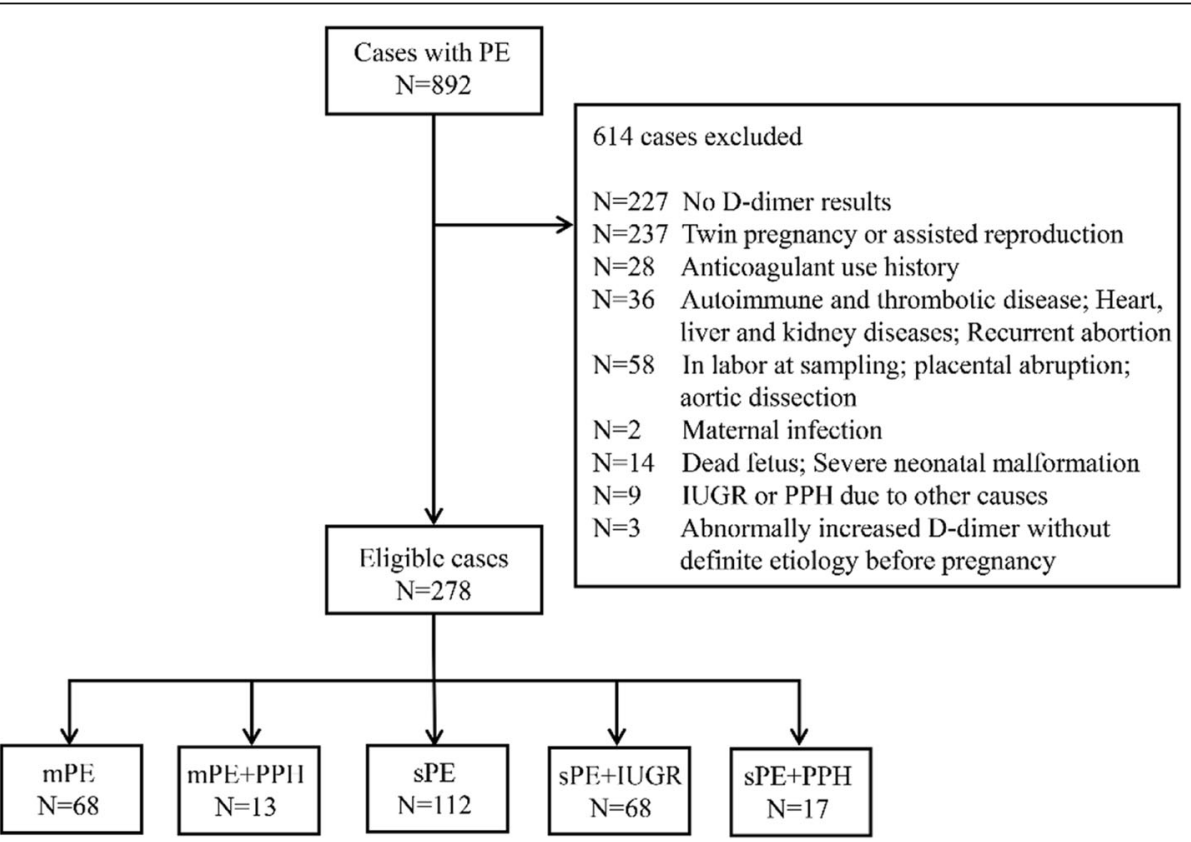

Fig. 1 The distribution of cases. $\mathrm{NP}=$ normal pregnancy, $\mathrm{GW}=$ gestational week, $\mathrm{mPE}=$ mild preeclampsia, $\mathrm{sPE}=$ severe preeclampsia, $\mathrm{PPH}=$ postpartum hemorrhage, IUGR= intrauterine growth restriction 
International Society for the Study of Hypertension in Pregnancy (ISSHP) guidelines [15] and the American College of Obstetrics and Gynecology (ACOG) guidelines. Cases were considered as severe preeclampsia if they met any of the following criteria: blood pressure $\geq 160 / 110 \mathrm{mmHg}$, thrombocytopenia, maternal organ injury (e. g. liver, kidney), pulmonary edema, new-onset headache or visual symptoms, or uteroplacental dysfunction, such as intrauterine growth restriction. IUGR was defined as the estimated fetal weight was less than the 10th percentile for gestational age and then verified after birth. The PPH was used to describe that the amount of blood loss was more than $500 \mathrm{ml}$ within 24 hours after vaginal delivery and more than $1000 \mathrm{ml}$ after cesarean section. Pregnant women with immunological diseases, hepatitis, pre-existing renal disease, hematological diseases, malignancy, deep venous thrombosis, recurrent spontaneous abortion, smoking history, anticoagulant drug-use history, assisted reproduction, twin pregnancy, placental abruption, stillbirth, and clinical chorioamnionitis were excluded. Those who were in labor at blood sampling were also excluded.

Clinical data including age, body mass index (BMI), gravidity, parity, gestational age, blood pressure on admission and pregnancy outcomes were collected from the medical record database. Blood samples were collected before delivery or during antenatal care. The tests of D-dimer and fibrinogen quantification were carried out according to the manufacturer's guidelines (Stago STA-R Evolution, France). D-dimer levels were measured by the immunoturbidimetry assay and fibrinogen levels were measured by the Clauss method. All the measurements were done with the same instrument and methodology.

Statistical analysis was performed using SPSS 25.0 software. The normality was analyzed by the KolmogorovSmirnov test. Continuous variables conformed to the normal distribution, were presented as mean \pm standard deviation (SD) and analyzed by student t-test or one-way ANOVA with LSD post hoc. Continuous variables that did not conform to the normal distribution, such as Ddimer and fibrinogen, were presented as median and interquartile range and analyzed by Mann-Whitney $\mathrm{U}$ test. Categorical variables, presented as percentages (\%), were analyzed by Pearson's Chi-square test. We conducted stratified analyses by the gestational age at sampling ( $<32$ weeks, 32-36 weeks, $>36$ weeks) in comparing D-dimer and fibrinogen between the sPE and sPE+IUGR groups. Logistic regression was used to analyze the relationship between biochemical indexes and PE combined with $\mathrm{PPH}$, adjusted for potential confounding factors, including gestational age at sampling, gestational age at onset, gestational age at delivery, age, BMI, scarred uterus, systolic blood pressure (SBP) and diastolic blood pressure (DBP) at admission. These confounders were selected because they were associated with D-dimer and fibrinogen levels or might influence the incidence of PPH. Hosmer-Lemeshow-Test was used to evaluate the goodness of fit of the model and the $P$-value was 0.377 . Furthermore, the receiver operating characteristic curve (ROC) was taken to evaluate their predictive values in PE complicated with PPH. $P$-value $<0.05$ was considered statistically significant.

\section{Results}

\section{Subject characteristics}

The study flow was shown in Fig. 1. A total of 892 preeclamptic patients were screened according to the inclusion criteria. 614 cases were excluded due to missing Ddimer value, twin pregnancy, assisted reproduction, anticoagulant use history, or other maternal and fetal diseases that influenced D-dimer and fibrinogen plasma levels. Finally, 278 eligible cases were divided into five groups: $\mathrm{mPE}(\mathrm{n}=68), \mathrm{mPE}+\mathrm{PPH}(\mathrm{n}=13), \operatorname{sPE}(\mathrm{n}=112)$, sPE $+P P H(n=17), s P E+I U G R(n=68)$. Clinical characteristics including maternal age, gravidity, parity, systolic blood pressure (SBP) and diastolic blood pressure (DBP) at admission were similar between the $\mathrm{mPE}$ and $\mathrm{mPE}+$ $\mathrm{PPH}$ groups, sPE and sPE $+\mathrm{PPH}$ groups, sPE and sPE+ IUGR groups, respectively $(P>0.05)$. Women who gave birth to neonates with IUGR had lower BMIs $(P<0.05)$. There were no significant differences in gestational age at onset and delivery, neonatal birth weight and 1-5 min Apgar scores between the $\mathrm{mPE}$ and $\mathrm{mPE}+\mathrm{PPH}$ groups $(P>0.05)$. The gestational age at sampling showed no statistical significance between the $\mathrm{mPE}$ and $\mathrm{mPE}+\mathrm{PPH}$ groups $(P>0.05)$, while it was lower in the sPE+IUGR/ $\mathrm{PPH}$ groups compared with that in the sPE group $(P<$ 0.05). Neonatal birthweight and Apgar scores in the sPE+IUGR and sPE+PPH groups were markedly lower than those in the sPE group, which might be related to smaller gestational age in sPE with IUGR/PPH $(P<$ 0.05). However, the comparison of stratified gestational age at sampling ( $<32$ weeks, 32-36 weeks, $>36$ weeks) between the sPE and sPE+IUGR groups showed no difference $(P>0.05)$ (Table 1$)$.

\section{D-dimer and Fibrinogen in PE Complicated with PPH}

The level of plasma D-dimer in the $\mathrm{mPE}+\mathrm{PPH}$ group was numerically higher than that in the mPE group, but the difference was not statistically significant $(1.17(0.97$, $1.76)$ versus $1.30(1.17,2.33) \mu \mathrm{g} / \mathrm{ml}, P>0.05)$. However, severe preeclamptic women complicated with $\mathrm{PPH}$ had observably higher D-dimer plasma levels than those without PPH $(2.02(1.73,2.50)$ versus $1.37(0.94,1.91)$ $\mu \mathrm{g} / \mathrm{ml}, P<0.05)$. There was no significant difference in the level of plasma fibrinogen between the patients with $\mathrm{PPH}$ and the patients without $\mathrm{PPH}$ either in $\mathrm{mPE}$ or $\mathrm{SPE}$ 
Table 1 Baseline characteristics of the sPE, sPE+PPH and sPE+IUGR groups

\begin{tabular}{|c|c|c|c|c|c|c|c|c|}
\hline & $\begin{array}{l}\mathrm{mPE} \\
(\mathrm{n}=68)\end{array}$ & $\begin{array}{l}\mathrm{mPE}+\mathrm{PPH} \\
(\mathrm{n}=13)\end{array}$ & $P^{a}$ & $\begin{array}{l}\text { sPE } \\
(n=112)\end{array}$ & $\begin{array}{l}\text { sPE+IUGR } \\
(\mathrm{n}=68)\end{array}$ & $\begin{array}{l}\text { sPE+PPH } \\
(n=17)\end{array}$ & $P^{\mathbf{b}}$ & $P^{c}$ \\
\hline Age & $30.34 \pm 5.60$ & $30.77 \pm 6.06$ & 0.802 & $30.94 \pm 5.51$ & $31.37 \pm 5.18$ & $31.18 \pm 4.83$ & 0.605 & 0.866 \\
\hline $\mathrm{BMI}\left(\mathrm{kg} / \mathrm{m}^{2}\right)$ & $29.69 \pm 3.76$ & $29.72 \pm 4.30$ & 0.978 & $28.84 \pm 3.64$ & $27.69 \pm 3.69$ & $27.15 \pm 3.30$ & 0.043 & 0.075 \\
\hline Gravidity & $2(1,3)$ & $2(1,4)$ & 0.543 & $3(1,4)$ & $3(2,4)$ & $3(2,4)$ & 0.333 & 0.546 \\
\hline Parity & $0(0,1)$ & $1(0,1)$ & 0.188 & $1(0,1)$ & $1(0,1)$ & $1(0,1)$ & 0.853 & 0.817 \\
\hline Scarred uterus (\%) & $16(23.5 \%)$ & $2(15.4 \%)$ & 0.777 & $37(33.0 \%)$ & $23(33.8 \%)$ & $5(29.4 \%)$ & 0.913 & 0.766 \\
\hline SBP at admission $(\mathrm{mmHg})$ & $142.56 \pm 11.42$ & $146.62 \pm 13.07$ & 0.255 & $163.78 \pm 17.58$ & $159.90 \pm 20.27$ & $166.24 \pm 16.08$ & 0.177 & 0.588 \\
\hline DBP at admission $(\mathrm{mmHg})$ & $89.91 \pm 8.96$ & $93.69 \pm 11.69$ & 0.189 & $100.11 \pm 12.42$ & $98.66 \pm 13.14$ & $103.59 \pm 8.89$ & 0.460 & 0.268 \\
\hline Gestational age at onset (weeks) & $\begin{array}{l}37.71(36.04 \\
39.39)\end{array}$ & $\begin{array}{l}37.00 \\
(33.64,40.07)\end{array}$ & 0.872 & $\begin{array}{l}33.50 \\
(30.00,36.57)\end{array}$ & $\begin{array}{l}30.93 \\
(28.14,35.25)\end{array}$ & $\begin{array}{l}30.00 \\
(27.36,32.50)\end{array}$ & 0.047 & 0.027 \\
\hline $\begin{array}{l}\text { Gestational age at sampling } \\
\text { (weeks) }\end{array}$ & $\begin{array}{l}38.36(37.32 \\
39.54)\end{array}$ & $\begin{array}{l}39.29 \\
(36.57,40.42)\end{array}$ & 0.414 & $\begin{array}{l}34.93 \\
(32.18,37.96)\end{array}$ & $\begin{array}{l}33.71 \\
(31.29,36.57)\end{array}$ & $\begin{array}{l}30.57 \\
(28.50,35.36)\end{array}$ & 0.005 & 0.006 \\
\hline $\begin{array}{l}\text { Gestational age at delivery } \\
\text { (weeks) }\end{array}$ & $\begin{array}{l}38.86(37.86 \\
39.96)\end{array}$ & $\begin{array}{l}39.71 \\
(37.79,40.71)\end{array}$ & 0.306 & $\begin{array}{l}35.57 \\
(32.39,38.14)\end{array}$ & $\begin{array}{l}33.00 \\
(30.75,36.43)\end{array}$ & $\begin{array}{l}31.14 \\
(29.14,35.57)\end{array}$ & 0.004 & 0.004 \\
\hline$<32$ & & & & $\begin{array}{l}30.43 \\
(28.26,31.21)\end{array}$ & $\begin{array}{l}30.64 \\
(29.79,31.29)\end{array}$ & & 0.254 & \\
\hline $32-36$ & & & & $\begin{array}{l}34.29 \\
(33.32,34.82)\end{array}$ & $\begin{array}{l}34.14 \\
(32.93,35.00)\end{array}$ & & 0.197 & \\
\hline$>36$ & & & & $\begin{array}{l}38.07 \\
(37.14,39.29)\end{array}$ & $\begin{array}{l}37.36 \\
(36.68,38.89)\end{array}$ & & 0.144 & \\
\hline Cesarean rate (\%) & $41(60.3 \%)$ & $4(30.8 \%)$ & 0.050 & $97(86.6 \%)$ & $57(83.8 \%)$ & $15(88.2 \%)$ & 0.607 & 1.000 \\
\hline Birth weight(g) & $\begin{array}{l}3375 \\
(2900,3737.5)\end{array}$ & $3480(3290,3805)$ & 0.222 & $\begin{array}{l}2570 \\
(1657.5,2995)\end{array}$ & $\begin{array}{l}1485 \\
(1090,1972.5)\end{array}$ & $1360(915,1825)$ & 0.000 & 0.000 \\
\hline 1 min Apgar score & $10(9,10)$ & $10(9,10)$ & 0.182 & $9(9,10)$ & $9(8,10)$ & $8(6,9)$ & 0.020 & 0.000 \\
\hline $5 \mathrm{~min}$ Apgar score & $10(10,10)$ & $10(10,10)$ & 0.409 & $10(10,10)$ & $10(9,10)$ & $9(8,10)$ & 0.078 & 0.000 \\
\hline
\end{tabular}

Data are given as mean $\pm S D, n(\%)$ or median (interquartile range, IQR)

${ }^{a}$ The comparison between $\mathrm{mPE}$ group and $\mathrm{mPE}+\mathrm{PPH}$ group

b The comparison between SPE group and SPE+IUGR group

c The comparison between $\mathrm{SPE}$ group and $\mathrm{SPE}+\mathrm{PPH}$ group

groups (Table 2). Multivariate logistic regression showed that higher D-dimer was associated with $\mathrm{PPH}$ in $\mathrm{SPE}$ (odds ratio (OR) [95\% CI]: 1.991 [1.236-3.208], $P=$ 0.005; adjusted odds ratio (aOR) [95\% CI]: 3.093 [1.5276.264], $P=0.002$ ), while fibrinogen was independent with PPH (OR [95\% CI]: 0.720 [0.420-1.233], $P=0.231$; aOR [95\% CI]: 1.425 [0.682-2.979], $P=0.347$ ), after adjusting for gestational age at sampling, gestational age at onset, gestational age at delivery, age, BMI, scarred uterus, SBP at admission, DBP at admission. Furthermore, we estimated the value of D-dimer in predicting $\mathrm{PPH}$ in severe preeclamptic women by the ROC analysis.
The cut-off point for D-dimer plasma level was 1.555 $\mu \mathrm{g} / \mathrm{ml}$ with a sensitivity of $94.1 \%$ and a specificity of 58.6\% (Fig. 2, Table 3).

\section{D-dimer and Fibrinogen in SPE Complicated with IUGR}

The comparisons of D-dimer and fibrinogen were shown in Table 4. In sub-analyses stratified by gestational age at sampling ( $<32$ weeks, 32-36 weeks, $>36$ weeks), there were no significant differences in D-dimer and fibrinogen between the sPE group and the sPE+IUGR group $(P$ $>0.05)$.

Table 2 D-dimer and fibrinogen in the PE and PE+PPH groups

\begin{tabular}{llllll}
\hline & $\begin{array}{l}\mathrm{mPE} \\
(\mathbf{n}=\mathbf{6 8})\end{array}$ & $\begin{array}{l}\mathbf{m P E}+\mathbf{P P H} \\
(\mathbf{n}=\mathbf{1 3})\end{array}$ & $\boldsymbol{P}^{\mathbf{a}}$ & $\begin{array}{l}\mathbf{s P E} \\
(\mathbf{n}=\mathbf{1 1 2})\end{array}$ & $\begin{array}{l}\text { sPE+PPH } \\
(\mathbf{n}=\mathbf{1 7})\end{array}$ \\
\hline D-dimer $(\mu \mathrm{g} / \mathrm{mL})$ & $1.17(0.97,1.76)$ & $1.30(1.17,2.33)$ & 0.124 & $1.37(0.94,1.91)$ & $2.02(1.73,2.50)$ \\
Fibrinogen $(\mathrm{g} / \mathrm{L})$ & $4.73(4.31,5.40)$ & $5.13(4.37,5.31)$ & 0.537 & $4.52(3.95,5.22)$ & $3.95(3.73,5.38)$ \\
\hline
\end{tabular}

Data are given as median (interquartile range, IQR)

${ }^{a}$ The comparison between $\mathrm{mPE}$ group and $\mathrm{mPE}+\mathrm{PPH}$ group

${ }^{b}$ The comparison between sPE group and $\mathrm{SPE}+\mathrm{PPH}$ group 


\section{ROC curve}

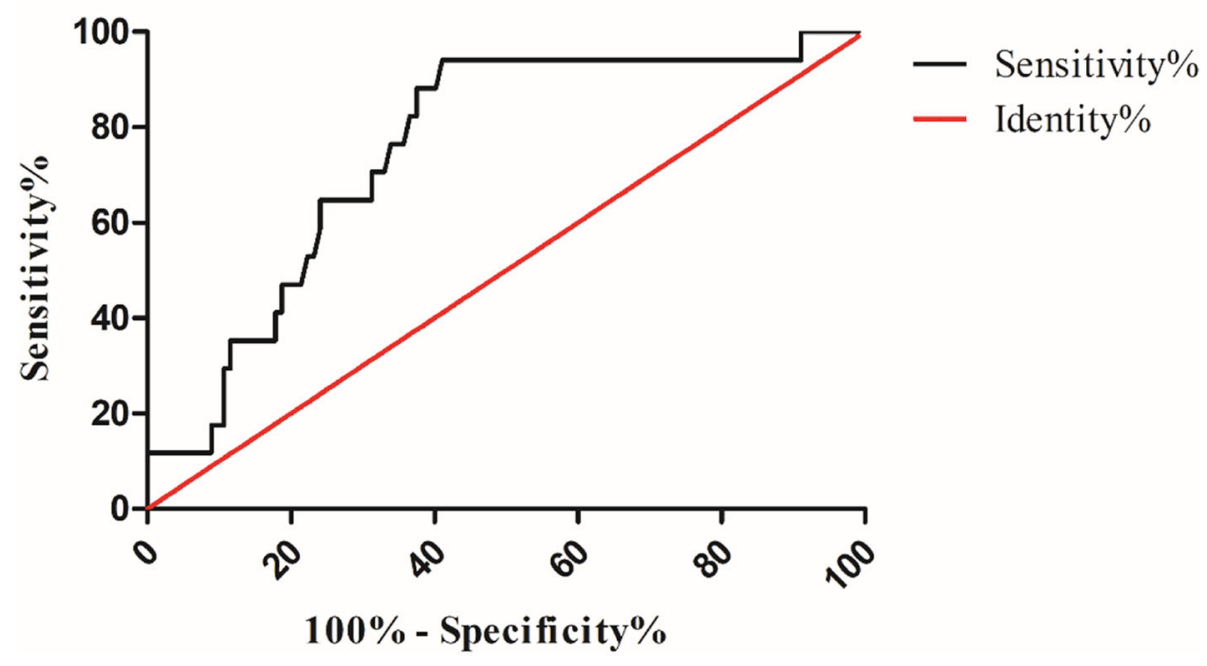

Fig. 2 ROC curve of D-dimer

\section{Discussion}

Preeclampsia is the second common cause of maternal death worldwide. Preeclampsia-related complications such as PPH and IUGR pose an increased rate of preterm labor and cesarean section [16]. To date, numerous studies focused on finding ideal biomarkers regarding coagulation and fibrinolytic systems, such as D-dimer, fibrinogen, plasminogen activator Inhibitor-1 (PAI-1), tissue-type plasminogen activator ( $t$-PA), for aiding in the early prediction of $\mathrm{PE}$ before manifestations occur $[9,13,17-19]$. D-dimer and fibrinogen are easily available laboratory indexes. Thus, in this retrospective study, we chose D-dimer and fibrinogen as the potential indicators to discriminate between preeclampsia with $\mathrm{PPH} /$ IUGR and preeclampsia alone. To our knowledge, no similar studies have been reported.

Preeclamptic women are more likely to suffer $\mathrm{PPH}$ than low-risk women (10\% VS 0.4-1.3\%) [20]. Significantly higher D-dimer plasma levels were found in sPE group than those in $\mathrm{mPE}$ group [3,21,22], suggesting the more aggressively activated coagulation and fibrinolysis systems in severe preeclampsia [17], which might lead to more blood loss in sPE women. The D-dimer plasma level increased gradually with the increase of gestational age during normal pregnancy $[5,21,23]$. Our data showed that the median gestational age at sampling of the sPE group was 34.93 weeks, which was smaller than that in the sPE+PPH group (median: 30.57 weeks), while sPE women with $\mathrm{PPH}$ had higher D-dimer plasma level. Logistic regression revealed that $\mathrm{D}$-dimer was associated with the advancing risk of PPH in SPE women. Therefore, the antenatal D-dimer value might be associated with PPH in SPE. The cut-off D-dimer value in our study was $1.555 \mu \mathrm{g} / \mathrm{ml}$ with a sensitivity of $94.1 \%$ and a specificity of $58.6 \%$. Endo-Kawamura et al. found that Ddimer $>2.7 \mu \mathrm{g} / \mathrm{ml}$ in late pregnancy approximately doubled the risk of PPH [5]. The difference might be due to disparities in testing methods and subjects.

The results of studies as to the relationship between antenatal fibrinogen plasma levels and $\mathrm{PPH}$ were inconsistent. Charbit B et al. reported that no correlation was found between the antenatal fibrinogen plasma levels and PPH [24]. Conversely, Endo-Kawamura et al. found that the antenatal fibrinogen plasma level $<4.0 \mathrm{~g} / \mathrm{L}$ increased the PPH prevalence rate [5]. Moreover, the cutoff fibrinogen value was $3.3 \mathrm{~g} / \mathrm{L}$ in women with vaginal delivery but not cesarean section [25]. Pregnant women with preeclampsia are in a hypercoagulant state compared with normal pregnancy [9]. As it progresses to a more severe stage, more changes in coagulation and fibrinolysis indicators occur [17]. Compared with the $\mathrm{mPE}$ group, the sPE group showed significantly higher levels of plasma D-dimer and fibrinogen [3]. In our study, no significant difference in antenatal fibrinogen

Table 3 ROC curve of D-dimer for evaluation of sPE with PPH

\begin{tabular}{llllllll}
\hline Variables & $\begin{array}{l}\text { Cut- } \\
\text { off } \\
\text { value }\end{array}$ & Sensitivity & Specificity & AUC & $\boldsymbol{P}$ & $\frac{\mathbf{9 5}^{2} \mathrm{Cl}}{\text { Lower limit }}$ & Upper limit \\
\hline D-dimer & 1.555 & $94.1 \%$ & $58.6 \%$ & 0.752 & 0.001 & 0.639 & 0.865 \\
\hline
\end{tabular}


Table 4 D-dimer and fibrinogen in the sPE and sPE+IUGR groups stratified by different gestational age at sampling

\begin{tabular}{|c|c|c|c|}
\hline 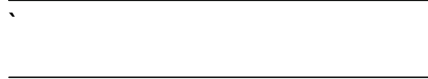 & $\begin{array}{l}\text { sPE } \\
n=112\end{array}$ & $\begin{array}{l}\text { sPE+IUGR } \\
n=68\end{array}$ & $P$ \\
\hline Gestational age $<32$ weeks & $n=26$ & $n=30$ & \\
\hline D-dimer $(\mu \mathrm{g} / \mathrm{mL})$ & $1.35(0.81,2.32)$ & $1.24(0.52,1.98)$ & 0.254 \\
\hline Fibrinogen ( $g / L)$ & $4.01(3.35,4.71)$ & $4.24(3.92,5.06)$ & 0.110 \\
\hline Gestational age $\geq 32$ and $\leq 36$ weeks & $n=36$ & $n=20$ & \\
\hline D-dimer $(\mu \mathrm{g} / \mathrm{mL})$ & $1.14(0.78,1.71)$ & $1.38(0.87,2.21)$ & 0.197 \\
\hline Fibrinogen ( $g / L)$ & $4.75(3.98,5.41)$ & $4.14(3.42,5.35)$ & 0.110 \\
\hline Gestational age $>36$ weeks & $n=50$ & $n=18$ & \\
\hline D-dimer $(\mu \mathrm{g} / \mathrm{mL})$ & $1.58(1.05,2.09)$ & $1.24(0.98,1.59)$ & 0.144 \\
\hline Fibrinogen ( $g / L)$ & $4.61(4.18,5.25)$ & $4.16(3.52,4.84)$ & 0.061 \\
\hline
\end{tabular}

Data are given as median (interquartile range, IQR)

was found between the $\mathrm{mPE}$ and $\mathrm{mPE}+\mathrm{PPH}$ groups or between the sPE and sPE+PPH groups. The conflicting results suggested that antenatal fibrinogen could not predict $\mathrm{PPH}$ no matter in women with normal pregnancy or with preeclampsia.

Both preeclampsia and IUGR were classified as the Great Obstetrical Syndromes, because they shared the same pathological mechanisms including inadequate uterine spiral artery remodeling and poor placentation [26]. Higher fibrinogen but not D-dimer in the third trimester was reported in women with IUGR [4]. But among preeclamptic women, those with IUGR did not have higher levels of plasma fibrinogen and D-dimer [19]. Similarly, our team found that the stratified comparisons of D-dimer and fibrinogen between the sPE group and the sPE+IUGR group showed no significant differences. Despite the maternal vascular lesions of PE is more serious than that of IUGR [27], we speculated that the lesions in preeclampsia with IUGR were comparable to those in preeclampsia alone, thus maternal serum indexes were similar between the two conditions.

Of note, this was the first report to describe the alterations of antenatal D-dimer and fibrinogen in preeclamptic women combined with PPH or IUGR. However, a limitation of this study was that D-dimer values were missing in some cases, which might lead to selection bias. Besides, this study used retrospective data and only associations but not causations could be derived. Our data cannot be a proof of D-dimer being predictive of preeclampsia in any form. Large prospective trials are needed to investigate the predictive value of $\mathrm{D}$ dimer in PPH in severe preeclampsia.

In conclusion, antenatal D-dimer level may be associated with PPH in severe preeclamptic women. In clinical practice, for sPE women with high levels of prenatal plasma D-dimer, we need to be aware of the occurrence of $\mathrm{PPH}$.

\section{Abbreviations}

PE: Preeclampsia; mPE: Mild preeclampsia; sPE: severe preeclampsia;

PPH: Postpartum hemorrhage; IUGR: Intrauterine growth restriction; OR: Odds ratio; Cl: Confidence interval; AT1: Anti-type-1 angiotensin II receptor; PAl1: Plasminogen activator inhibitor-1; ISSHP: International Society for the Study of Hypertension in Pregnancy; ACOG: American College of Obstetrics and Gynecology; BMl: Body mass index; SD: Standard deviation; ROC: Receiver operating characteristic curve; SBP: Systolic blood pressure; DBP: Diastolic blood pressure; t-PA: Tissue-type plasminogen activator

Acknowledgements

We would like to thank all the authors' work and the financial support by grants from Zhejiang province medical science and technology of China.

\begin{abstract}
Authors' contributions
HL.S contributed to the design of the work, analyzed the data and draft the article; SC.G, DR.D and XM.Z contributed to the acquisition of data; HJ.Y revised the manuscript and some statistical methods. Y.H revised it critically for important intellectual content and made final approval of the version to be published. All authors read and approved the final manuscript.
\end{abstract}

\section{Funding}

This work was funded by grants from Zhejiang province medical science and technology of China [grant number 2021KY215].

\section{Availability of data and materials}

The datasets used and/or analysed during the current study available from the corresponding author on reasonable request.

\section{Declarations}

Ethics approval and consent to participate

This study was performed in accordance with the Declaration of Helsinki and was approved by the Research Ethics Committee of the Second Affiliated Hospital of Wenzhou Medical University. Informed consent was obtained from all individual participants included in the study.

\section{Consent for publication}

Not applicable.

\section{Competing interests}

The authors declare that they have no competing interests.

\section{Author details}

${ }^{1}$ Department of Obstetrics and Gynecology, the Second Affiliated Hospital of Wenzhou Medical University, Wenzhou 325027, China. ${ }^{2}$ Department of Obstetrics and Gynecology, Wenzhou People Hospital, Wenzhou, China.

Received: 8 March 2021 Accepted: 29 August 2021

Published online: 05 September 2021

\section{References}

1. Haire G, Egan K, Parmar K, McKinnon T, Monteith C, O'Connor H, et al, Alterations in fibrin formation and fibrinolysis in early onset-preeclampsia: 
Association with disease severity. Eur J Obstet Gynecol Reprod Biol. 2019; 241:19-23.

2. Abalos E, Cuesta C, Grosso AL, Chou D, Say L. Global and regional estimates of preeclampsia and eclampsia: a systematic review. Eur J Obstet Gynecol Reprod Biol. 2013;170(1):1-7.

3. Duan Z, Li C, Leung WT, Wu J, Wang M, Ying C, et al. Alterations of Several Serum Parameters Are Associated with Preeclampsia and May Be Potential Markers for the Assessment of PE Severity. Dis Markers. 2020;2020:1-7.

4. Tetik K, Seçkin KD, Karslı FM, Sarıslan S, Çakmak B, Danışman N. Can we use as a marker the maternal serum levels of D-dimer and fibrinogen to predict intra uterin growth restriction? J Turkish Soc Obstetric Gynecol. 2014;11(4): 228-32.

5. Endo-Kawamura N, Obata-Yasuoka M, Yagi H, Ohara R, Nagai Y, Mayumi M, et al. Higher D-dimer level in the early third trimester predicts the occurrence of postpartum hemorrhage. J Perinat Med. 2016;44(5):551-6.

6. Carpani G, Bozzo M, Ferrazzi E, D'Amato B, Pizzotti D, Radaelli T, et al. The evaluation of maternal parameters at diagnosis may predict HELLP syndrome severity. J Matern Fetal Neonatal Med. 2009;13(3):147-51.

7. Macey MG, Bevan S, Alam S, Verghese L, Agrawal S, Beski S, et al. Platelet activation and endogenous thrombin potential in pre-eclampsia. Thromb Res. 2010;125(3):e76-81.

8. Chaiworapongsa T, Yoshimatsu J, Espinoza J, Kim YM, Berman S, Edwin S, et al. Evidence of in vivo generation of thrombin in patients with small-forgestational-age fetuses and pre-eclampsia. J Matern Fetal Neonatal Med. 2002;11(6):362-7.

9. Pinheiro MB, Gomes KB, Dusse LM. Fibrinolytic system in preeclampsia. Clin Chim Acta. 2013;416:67-71

10. Chaiworapongsa T, Chaemsaithong P, Yeo L, Romero R. Pre-eclampsia part 1: current understanding of its pathophysiology. Nat Rev Nephrol. 2014; 10(8):466-80.

11. Adam SS, Key NS, Greenberg CS. D-dimer antigen: current concepts and future prospects. Blood. 2009;113(13):2878-87.

12. Kim SJ, Ahn HJ, Park JY, Kim BJ, Hwang KR, Lee TS, et al. The clinical significance of D-dimer concentrations in patients with gestational hypertensive disorders according to the severity. Obstet Gynecol Sci. 2017; 60(6):542-8.

13. Pinheiro MB, Carvalho MG, Martins-Filho OA, Freitas LG, Godoi LC, Alpoim $\mathrm{PN}$, et al. Severe preeclampsia: are hemostatic and inflammatory parameters associated? Clin Chim Acta. 2014;427:65-70.

14. Pinheiro Mde B, Junqueira DR, Coelho FF, Freitas LG, Carvalho MG, Gomes $\mathrm{KB}$, et al. D-dimer in preeclampsia: systematic review and meta-analysis. Clin Chim Acta. 2012:414:166-70.

15. Brown MA, Magee LA, Kenny LC, Karumanchi SA, McCarthy FP, Saito S, et al. Hypertensive Disorders of Pregnancy: ISSHP Classification, Diagnosis, and Management Recommendations for International Practice. Hypertension. 2018;72(1):24-43.

16. Force USPST, Bibbins-Domingo K, Grossman DC, Curry SJ, Barry MJ, Davidson KW, et al. Screening for Preeclampsia: US Preventive Services Task Force Recommendation Statement. JAMA. 2017;317(16):1661-7.

17. Kobayashi T, Tokunaga N, Sugimura M, Kanayama N, Terao T. Predictive values of coagulation/fibrinolysis parameters for the termination of pregnancy complicated by severe preeclampsia. Semin Thromb Hemost. 2001;27(2):137-41.

18. Estelles A, Gilabert J, Aznar J, Loskutoff DJ, Schleef RR. Changes in the plasma levels of type 1 and type 2 plasminogen activator inhibitors in normal pregnancy and in patients with severe preeclampsia. Blood. 1989; 74(4):1332-8.

19. Schjetlein R, Haugen G, Wisloff F. Markers of intravascular coagulation and fibrinolysis in preeclampsia: association with intrauterine growth retardation. Acta Obstet Gynecol Scand. 1997;76(6):541-6.

20. Koopmans CM, van der Tuuk K, Groen H, Doornbos JP, de Graaf IM, van der Salm PC, et al. Prediction of postpartum hemorrhage in women with gestational hypertension or mild preeclampsia at term. Acta Obstet Gynecol Scand. 2014;93(4):399-407.

21. Kucukgoz Gulec U, Tuncay Ozgunen F, Baris Guzel A, Buyukkurt S, Seydaoglu G, Ferhat Urunsak I, et al. An analysis of C-reactive protein, procalcitonin, and D-dimer in pre-eclamptic patients. Am J Reprod Immunol. 2012;68(4):331-7.

22. Rodriguez-Pena Y, Ibanez-Pinilla M. Elevated levels of D-dimer tested by immunoturbidimetry are associated with the extent of severity of preeclampsia. Int J Gynaecol Obstet. 2020;150(2):241-7.
23. Han L, Liu X, Li H, Zou J, Yang Z, Han J, et al. Blood coagulation parameters and platelet indices: changes in normal and preeclamptic pregnancies and predictive values for preeclampsia. PLoS One. 2014;9(12):e114488.

24. Peyvandi F, Biguzzi E, Franchi F, Bucciarelli P, Acaia B, Zaina B, et al. Elevated prepartum fibrinogen levels are not associated with a reduced risk of postpartum hemorrhage. J Thromb Haemost. 2012;10(7):1451-3.

25. Yamada T, Akaishi R, Oda Y, Nishida R, Yamada T, Ishikawa S, et al. Antenatal fibrinogen concentrations and postpartum haemorrhage. Int J Obstet Anesth. 2014;23(4):365-70.

26. Marsal K. Preeclampsia and intrauterine growth restriction: placental disorders still not fully understood. J Perinat Med. 2017:45(7):775-7.

27. Burton G, Redman C, Roberts J, Moffett A. Pre-eclampsia: pathophysiology and clinical implications. BMJ. 2019;366:12381.

\section{Publisher's Note}

Springer Nature remains neutral with regard to jurisdictional claims in published maps and institutional affiliations.

\section{Ready to submit your research? Choose BMC and benefit from:}

- fast, convenient online submission

- thorough peer review by experienced researchers in your field

- rapid publication on acceptance

- support for research data, including large and complex data types

- gold Open Access which fosters wider collaboration and increased citations

- maximum visibility for your research: over $100 \mathrm{M}$ website views per year

At BMC, research is always in progress.

Learn more biomedcentral.com/submissions 